\title{
Primary pure squamous cell carcinoma
}

\section{of the duodenum: report of three cases}
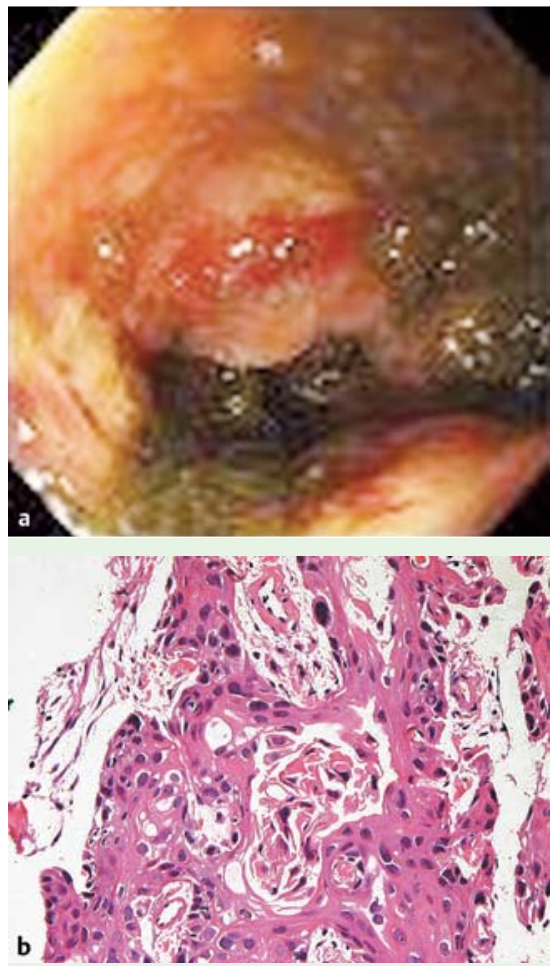

Fig. 1 Case 1. a Endoscopy showing an ulcerated and polypoid circumferential tumor in the duodenum. b Squamous cell carcinoma with keratinization (hematoxylin and eosin; magnification $\times 200$ ).

Carcinoma of the duodenum is very rare, and most duodenal carcinomas are adenocarcinomas [1]. A review of the English literature revealed only two cases of squamous cell carcinoma of the duodenum $[2,3]$, and one case of adenosquamous carcinoma [4]. Here, we report three cases of pure squamous cell carcinoma of the duodenum.

Case 1: A 75-year-old man was admitted to our hospital because of vomiting and weakness. An endoscopic examination revealed a circumscribed, obstructing tumor in the second part of the duodenum distal to the ampulla of Vater ( $\bullet$ Fig. 1 a). Eight biopsy samples were obtained, and all of them showed pure squamous cell carcinoma ( $\bullet$ Fig. $\mathbf{1 b}$ ). The patient was treated with chemotherapy and radiation, but he died of systemic metastasis 17 months after the first presentation.

Case 2: A 58-year-old woman presented with abdominal pain. An endoscopic examination revealed an ulcerated tumor in
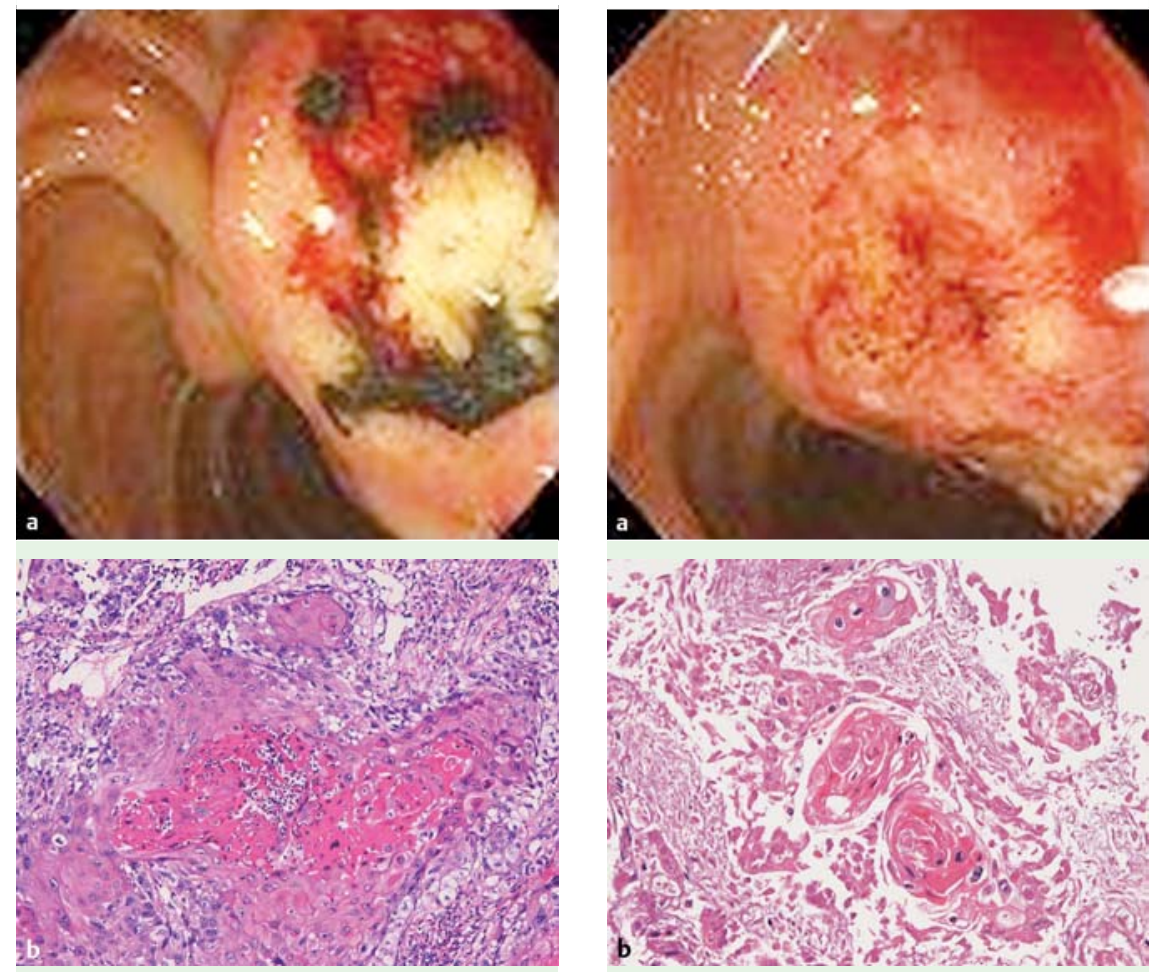

Fig. 2 Case 2. a Endoscopy showing an ulcerated tumor in the duodenum. b Squamous cell carcinoma with keratinization (hematoxylin and eosin; magnification $\times 200$ ).

the second part of the duodenum near the ampulla of Vater ( Fig. 2a). Seven biopsy samples were taken, and all of them showed pure squamous cell carcinoma ( Fig. 2b). The patient was treated with chemotherapy and radiation, but she died of metastasis 21 months later.

Case 3: A 54-year-old man presented with abdominal pain. Endoscopy revealed an ulcerated tumor in the second part of the duodenum distal to the ampulla ( Fig. 3a), and four biopsy samples were taken. All of them revealed pure squamous cell carcinoma ( Fig. 3 b). The patient was admitted to another specialist hospital for surgery.

In all the three cases, the imaging investigations at the first presentation did not reveal tumor in other locations, including the pancreas, and the duodenal tumors were different from ampullary tumor and pancreatic tumor. All the three tumors lacked differentiation into adenocarcinoma or neuroendocrine carcinoma.

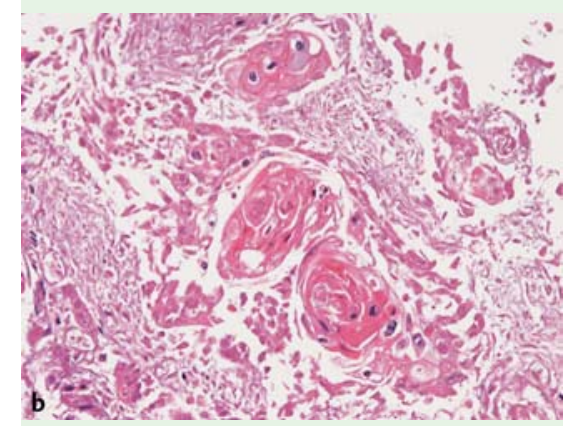

Fig. 3 Case 3. a Endoscopy showing an ulcerated tumor in the duodenum. $\mathbf{b}$ Squamous cell carcinoma with keratinization and intercellular bridges (hematoxylin and eosin; magnification $\times 200)$.

The pathogenesis of squamous cell carcinoma of the duodenum is still uncertain. Barnhill and colleagues [5] reported an interesting duodenal tumor with tripartite differentiation into adenocarcinoma, squamous cell carcinoma, and neuroendocrine carcinoma [5]. They speculated that the tumor in their case had arisen from duodenal pluripotent stem cells capable of differentiating into multiple cell types [5]. The tumors in all the present cases might also have arisen from such pluripotent stem cells.

Endoscopy_UCTN_Code_CCL_1AB_2AZ_3AB

\section{T. Terada}

Department of Pathology, Shizuoka City Shimizu Hospital, Shizuoka, Japan 


\section{References}

1 Wright NH, Pennazio M, Howe JR et al. Carcinoma of the small intestine. In: Hamilton SR, Aaltonen LA (eds). WHO classification of tumours. Pathology and genetics, tumor of the digestive system. Lyon IARC Press; 2000: $71-76$

2 Friedman E, Kwan MR, Cummins L. Squamous cell carcinoma of the transverse duodenum. Gastrointest Endosc 1986; 32: 99 101
3 von Delius S, Lersch C, Neu B et al. Squamous cell carcinoma of the duodenum as a rare cause of upper gastrointestinal bleeding. Endoscopy 2006; 38: 956

4 de la Cruz A, de la Cruz E, Sanchez MJ et al. Adenosquamous carcinoma of the duodenum: an immunohistochemical study. Pathol Res Pract 1993; 189: 481-485

5 Barnhill M, Hess E, Guccion JG et al. Tripartite differentiation in a carcinoma of the duodenum. Cancer 1994; 73: 266 - 272

\section{Bibliography}

DOI $10.1055 / \mathrm{s}-0029-1214940$

Endoscopy 2009; 41: E329-E330

(c) Georg Thieme Verlag KG Stuttgart · New York . ISSN 0013-726X

\section{Corresponding author}

\section{T. Terada, MD, PhD}

Department of Pathology

Shizuoka City Shimizu Hospital

Miyakami 1231 Shimizu-Ku

Shizuoka 424-8636

Japan

Fax: +81-54-3361315

piyo0111jp@yahoo.co.jp 